\title{
Effect of Nd:YAG laser irradiation on the characteristics of porous silicon photodetector
}

\author{
Raid A Ismail ${ }^{*}$ and Marwa K Abood ${ }^{*}$
}

\begin{abstract}
Electrical and photoresponse properties of a Al/porous silicon/crystalline silicon/Al structure (Al/PSi/Si/Al) are investigated under irradiation of Nd:YAG laser pulses. The effect of Nd-YAG laser irradiation on the morphological and structural properties of a porous silicon layer is also demonstrated. The porous Si layer is synthesized on a single crystalline p-type Si using electrochemical etching in aqueous hydrofluoric acid at a current density of 20 $\mathrm{mA} / \mathrm{cm}^{2}$ for a 40 -min etching time. The structure of the porous layer is investigated using atomic force microscopy and optical microscopy. The electrical properties and photodetector figures of merit (responsivity, detectivity, and carrier lifetime) are found to be dependent on the laser fluence.
\end{abstract}

Keywords: Porous silicon, Electrochemical etching, Nd:YAG laser, Photodetector, Figures of merit

\section{Background}

Porous silicon has drawn attention due its superior properties, required by many applications, as compared to crystalline. Porous silicon (PSi) technology is a simple and reliable technology creating nanostructured silicon, an advanced material for modern research. Porous silicon was discovered by Uhlir [1] in 1956 when performing an electrochemical etching of silicon [2]. It is defined as a composition of a silicon skeleton permeated by a network of pores. In other words, it is a network of silicon nanowires and nanoholes, which is formed when the crystalline silicon wafers are etched electrochemically in an electrolytic solution such as hydrofluoric (HF) acid [3]. In 1990, the strong visible photoluminescence (PL) [4] and electroluminescence [5] from PSi at room temperature have opened new possibilities for Si-based optoelectronic applications [6] Fabrication and characterization of porous silicon photodetectors by electrochemical etching were reported [7]. Few studies reported on the effect of laser irradiation on the PL and structural properties of porous silicon $[8,9]$. It was reported that the PL properties of porous silicon are dependent on irradiating laser energy density, a result that opened the door for using it in optical recording and storage information on the surface of silicon [10]. To the best of our knowledge, no paper has been

\footnotetext{
*Correspondence: raidismail@yahoo.com; marwa_kasim1987@yahoo.com
} Applied Science Department, University of Technology, Baghdad, Iraq reported stating the effect of laser irradiation on a porous silicon photodetector.

In the present work, we demonstrate the effect of pulsed Nd-Yag laser irradiation on the performance of a $\mathrm{Al} / \mathrm{PSi} /$ $\mathrm{Si} / \mathrm{Al}$ photodetector fabricated by electrochemical etching. Furthermore, the dependence of the morphological and structural properties of the porous silicon layer on laser fluence is presented.

\section{Methods}

A mirror-like monocrystalline p-type silicon wafer of 10 $\Omega \mathrm{cm}$ electrical resistivity and (111) orientation was used as a substrate. The silicon wafer was cut into $1 \times 1.5 \mathrm{~cm}$ substrates which were cleaned with ethanol and an ultrasonic bath device for 5 min to remove dirt, immersed in hydrofluoric acid in order to get rid of the native oxide layer for $3 \mathrm{~min}$, and then rinsed in deionized water. The porous layer was formed by electrochemical etching in ethanol/HF mixture (1:2; 40\% HF and 99\% ethanol) at a current density of $20 \mathrm{~mA} / \mathrm{cm}^{2}$ for $40 \mathrm{~min}$ in dark conditions at $300 \mathrm{~K}$. Ethanol was added to the HF solution in order to improve the wettability of the acid, allow the diffusion of $\mathrm{F}$ ions into pores, improve the PSi layer uniformity by removing the hydrogen bubbles, help moisten the silicon surface, and improve reproducibility [11]. The samples were then cleaned and air dried. Figure 1 shows a schematic diagram of the electrochemical anodization system used for PSi formation.

\section{望}




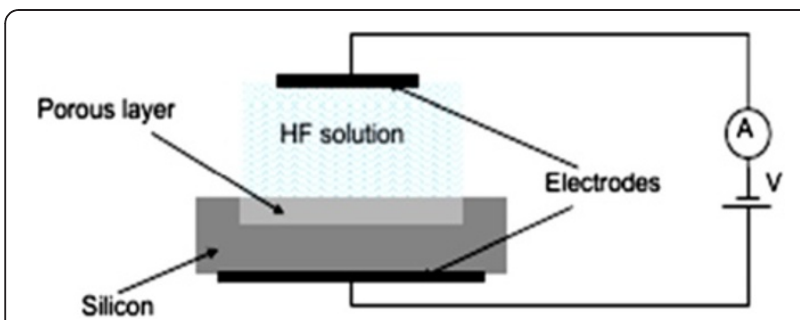

Figure 1 Schematic diagram of the electrochemical anodization system.

The porosity $(P \%=71 \%)$ and thickness $\left(t_{\mathrm{psi}}=50.1 \mu \mathrm{m}\right)$ of the PSi layer were calculated by measuring the weight of the samples before and after the etching process using Equations 1 and 2. Mettler AE160 digital steelyard (Mettler-Toledo, Columbus, OH, USA) with an accuracy of $10^{-4} \mathrm{gm}$ was used to weigh the samples.

$$
\begin{aligned}
& P(\%)=\frac{M_{1}-M_{2}}{M_{1}-M_{3}} \\
& t_{\mathrm{psi}}=\frac{M_{1}-M_{3}}{A \times D_{\mathrm{si}}}
\end{aligned}
$$

where $M_{1}$ is the wafer weight before anodization, $M_{2}$ is the weight after anodization, $M_{3}$ is the weight after a rapid dissolution of the whole porous layer in $3 \% \mathrm{KOH}$ solution, $A$ is the etched area $\left(\mathrm{cm}^{2}\right)$, and $D_{\mathrm{si}}$ is the density of silicon in $\mathrm{g} / \mathrm{cm}^{3}$ [12]. A pulsed Nd-YAG laser system type (Guangzhou Huafei Tongda Technology Co., China), providing pulses at 1,064-nm wavelength and a pulse duration of $10 \mathrm{~ns}$, was used for treatment of a porous Si layer at different fluences of 20,40 , and $60 \mathrm{~mJ} / \mathrm{cm}^{2}$ in air at room temperature. The morphology and root mean square (RMS) roughness of the porous layer were measured using atomic force microscopy (AFM; AA3000 scanning probe microscopy provided by Angstrom Advanced Inc., Braintree, MA, USA). To investigate the electrical and photoresponse characteristics of photodetectors, ohmic contacts were made on both porous and back surfaces by depositing aluminum with a thickness of $150 \mathrm{~nm}$ through a mask using a thermal resistive technique followed by annealing under a vacuum at $300^{\circ} \mathrm{C}$ for 15 min which was made to satisfy the ohmic contact. The cross-sectional view of the $\mathrm{Al} / \mathrm{PSi} / \mathrm{Si} / \mathrm{Al}$ structure is depicted in Figure 2.
Al thin film

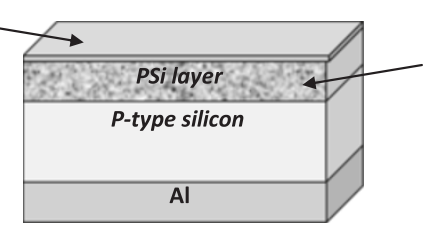

Laser treated layer
Figure 2 Cross- sectional view of the Al/PSi/Si/Al photodetector.
Dark and illuminated current-voltage $(I-V)$ characteristics of the photodetector were investigated using an electrometer, a power supply, and a halogen lamp. Capacitancevoltage $(C-V)$ measurements were carried out using a Fluke PM6306 programmable RCL meter (Fluke Calibration, Everett, WA, USA) with $1 \mathrm{MHz}$. The photosensitivity of the photodetector was investigated in the wavelength range of 400 to $1,000 \mathrm{~nm}$ with the aid of a Jobin Yvon monochromator (HORIBA Jobin Yvon Inc., Edison, NJ, USA) and a calibrated Si power meter. Carrier lifetime of the detector was measured using a stroboscope and $100 \mathrm{MHz}$ oscilloscope (CS-1021, Kenwood Corporation, Tokyo, Japan).

\section{Results and discussion}

The AFM images of the porous layer show a rough surface structure with a number of nanosized pores as seen in Figure 3. The AFM investigation showed some variation in morphology of the porous silicon layer before and after laser irradiation.

The 3D AFM image of the laser-treated layer scanned over a $5 \times 5 \mu \mathrm{m}$ region reveals that the porous silicon comprises inhomogeneous and large numbers of irregular silicon pillars and voids distributed randomly over the surface. An increase in the RMS of the surface roughness and height of grains were noticed after increasing laser fluence as displayed in Table 1. The formation of a pyramid-like hillock surface was observed too after laser irradiation. Increasing of the RMS after laser irradiation is ascribed to the re-melt of porous layer associates with rapid solidification that produces a rough surface. The solidification process $\left(10^{3}\right.$ to $\left.10^{10} \mathrm{~K} / \mathrm{s}\right)$ is so fast which in turn results in the formation of ripples [13].

The AFM results indicate that the overall structure of the porous $\mathrm{Si}$ layer depends strongly upon the laser fluence of the irradiating laser. Pore diameters and spacing can vary over a wide range on the nanometer scale. The results also show that after laser irradiation, the layer surface becomes more compact. This compactness is due to the recrystallization of the top layer. The same behavior was observed in other works conducted on a photothermal annealing field [14]. The surface recrystallization of the top layer is attributed to the reduction of the surface energy [15]. Figure 4 shows the optical micrographs of porous silicon before and after laser irradiation. It is clear from Figure 4a that the silicon surface was converted to a porous structure after electrochemical etching and that the pores are non-uniformly distributed over the etched surface; some of these pores have circular shape. The effect of laser irradiation on the microstructure of porous silicon is presented in Figure 4b.

The irradiated zone is not uniform because the etched surface has different grain sizes due to uneven spatial distribution of the used laser beam (Gaussian mode). On 

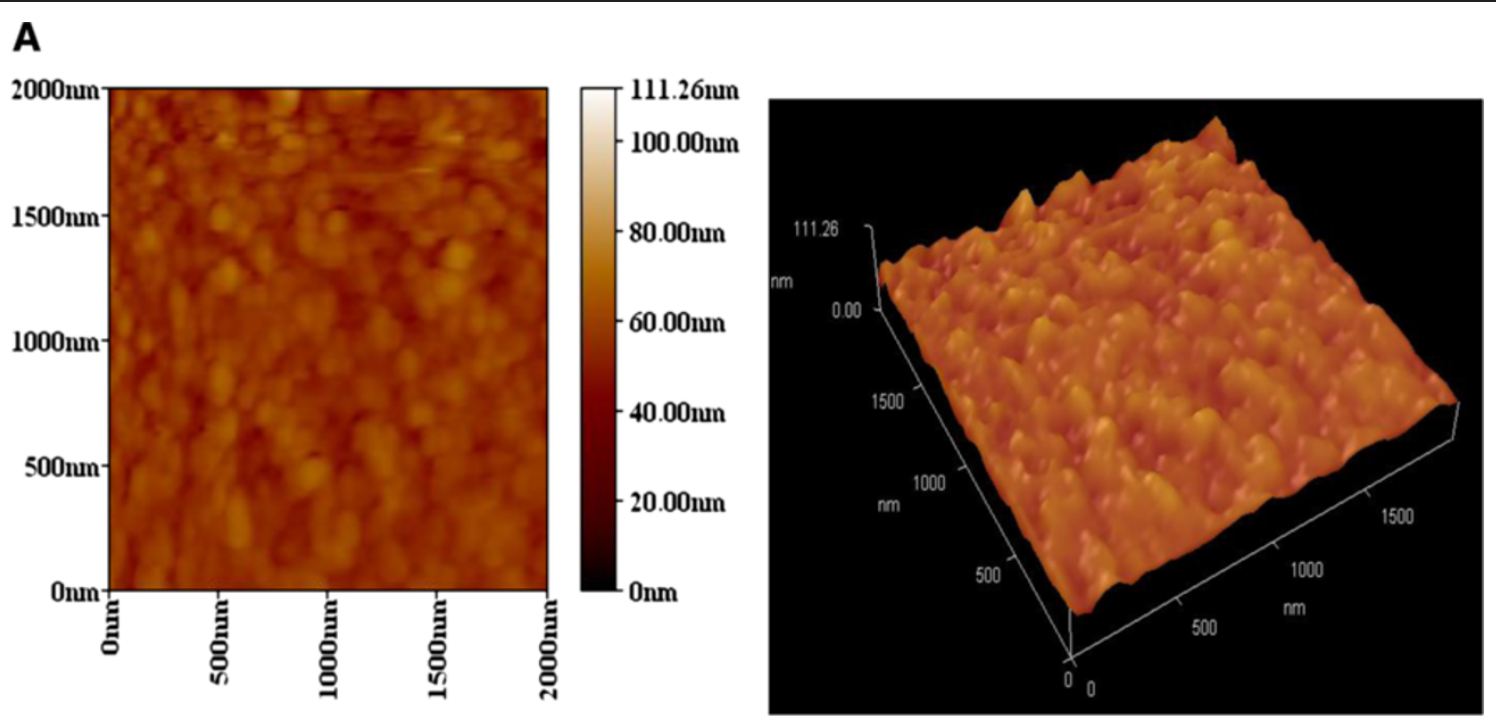

B
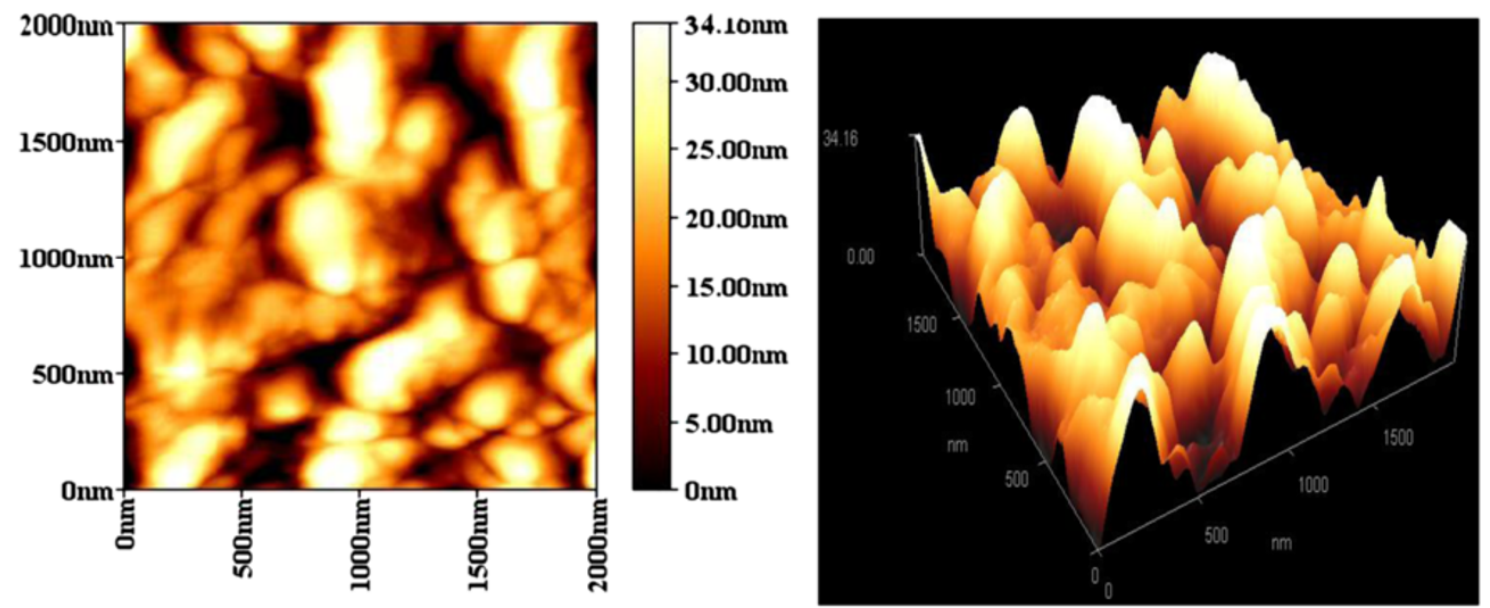

C

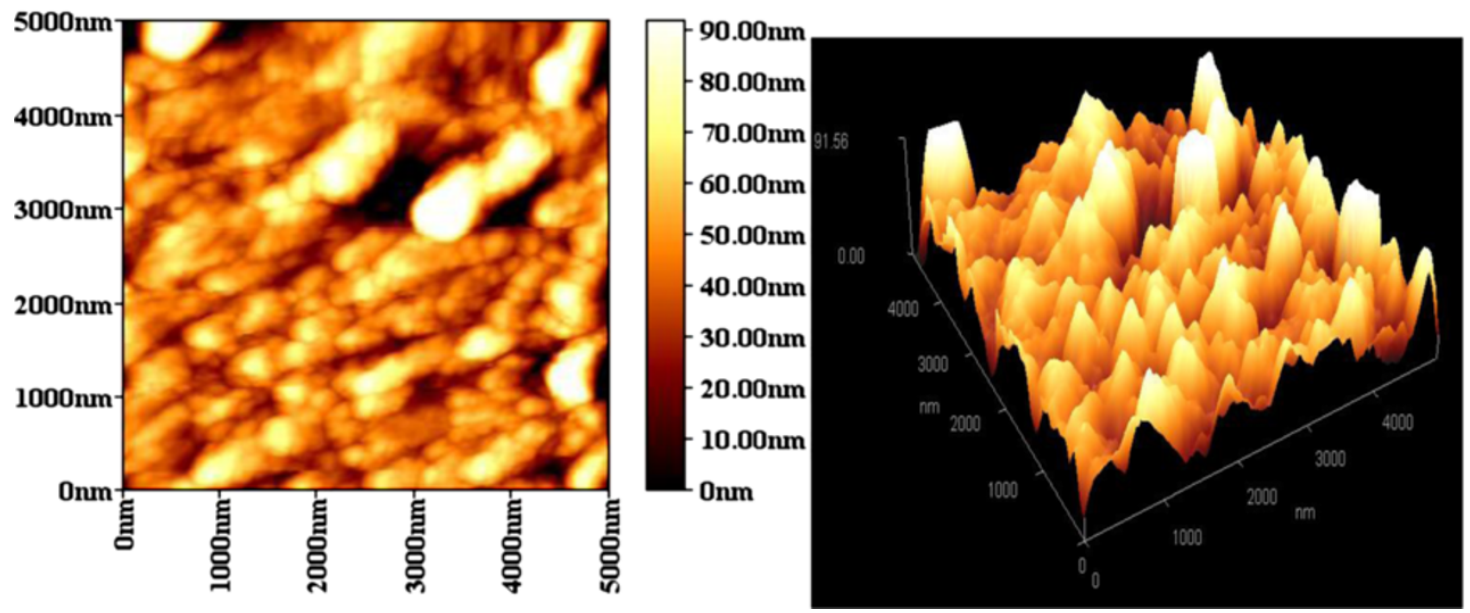

Figure 3 AFM surface morphology of a porous Si layer prepared for porous silicon. (A) Before laser irradiation and with laser irradiation with (B) $40 \mathrm{~mJ} / \mathrm{cm}^{2}$ and $(\mathbf{C}) 60 \mathrm{~mJ} / \mathrm{cm}^{2}$. 
Table 1 Values of RMS, average grain size, and size determined from AFM

\begin{tabular}{llll}
\hline $\begin{array}{l}\text { Laser fluence } \\
\left(\mathbf{m J} / \mathbf{c m}^{2}\right)\end{array}$ & $\begin{array}{l}\text { Average diameter } \\
(\mathbf{n m})\end{array}$ & $\begin{array}{l}\text { RMS } \\
(\mathbf{n m})\end{array}$ & $\begin{array}{l}\text { Size } \\
(\mathbf{n m})\end{array}$ \\
\hline 0 & 53.7 & 4.72 & 30.3 \\
20 & 65 & 6 & 31.7 \\
40 & 84.58 & 8.26 & 33.7 \\
60 & 227.69 & 17.5 & 89.3 \\
\hline
\end{tabular}

the other hand, irregular pore shapes are a result of the non-uniform chemical interaction between $\mathrm{HF}$ and $\mathrm{Si}$. The porous Si surface irradiated with $20 \mathrm{~mJ} / \mathrm{cm}^{2}$ showed melting regions; the macrospores are disappearing and their color becomes shinny (whitish regions), an indication of crystallization formation.

Dark $I-V$ characteristics of the $\mathrm{Al} / \mathrm{PSi} / \mathrm{Si} / \mathrm{Al}$ structure before and after laser irradiation using different laser fluencies are shown in Figure 5, where appreciable rectification is noticed. The positive axis of the $I-V$ plot corresponds to a positive bias voltage (forward bias) applied to the PSi. These $I-V$ characteristics are similar to those of the $\mathrm{p}-\mathrm{n} \mathrm{Si}$ junction but with a lower slope. This is because the $\mathrm{Al} / \mathrm{PSi} / \mathrm{Si} / \mathrm{Al}$ structure consists of two junctions connected in a series, the Al/PSi Schottky (due to high resistance of porous Si layer) junction and the PSi/Si heterojunction. This in good agreement with published data [16].

The forward current of the photodetector is increased after laser irradiation due to a decrease of the resistivity of the porous layer. This reduction comes from the improvement in the crystallinity of the porous layer. Irradiation at a high laser fluence $\left(60 \mathrm{~mJ} / \mathrm{cm}^{2}\right)$ increases the resistivity of the porous layer due to the generation of a structural defect in the irradiated area such as the recombination center or trapping center which has deep energy levels in the band gap of the porous Si [17]. From the dark ( $\ln I_{f^{-}} V$ ) characteristics of the $\mathrm{Al} / \mathrm{PSi} / \mathrm{Si} / \mathrm{Al}$ structure, the ideality factor $(n)$ and the saturation current $\left(I_{\mathrm{S}}\right)$ were deduced and calculated according to the following equation:

$$
n=\frac{q}{k_{B} T} \frac{\Delta V}{\operatorname{In} \frac{I}{I_{s}}}
$$

Figure 6 demonstrates the effect of laser fluence on the ideality factor of the photodetectors. The ideality factor was decreased when the photodetectors were irradiated with a laser fluence smaller than $60 \mathrm{~mJ} / \mathrm{cm}^{2}$ due to the increase of the forward current, but it increased slightly when the photodetector was irradiated with $60 \mathrm{~mJ} / \mathrm{cm}^{2}$.

It is obvious from Figure 7 that the forward current contains a hysteresis loop (denoted by arrows); when measuring the $I-V$ characteristics, the curve obtained when varying the voltage in an increasing manner was lower than that recorded when decreasing the voltage as shown in Figure 7. These loops could be attributed to the slow capture centers caused by the holes [18]. No hysteresis loop appeared on the reverse current. The hysteresis loops were noticed for all synthesized diodes.

Figure 8 shows the effect of laser irradiation on the photodetector photocurrent under the effect of reverse bias. A significant increase in the photocurrent was noticed when irradiating with a laser fluence of $40 \mathrm{~mJ} / \mathrm{cm}^{2}$. This is probably due to an increase in the width of the depletion layer which in turn increases the number of absorbed photons and the generated $\mathrm{e}-\mathrm{h}$ pairs.

Irradiation with higher laser fluence leads to decreases in the photocurrent. The dark $C-V$ characteristics of $\mathrm{Al} / \mathrm{PSi}$ / $\mathrm{c}-\mathrm{Si} / \mathrm{Al}$ photodetectors were measured before and after laser irradiation. The total capacitance $(C)$ of the photodetector can be described by two sire capacitors, one corresponding to junction capacitance $C_{\mathrm{j}}$ (PSi-c-Si junction) and the other to the geometric capacitor $C_{\mathrm{g}}$ (Al-PSi junction). The total capacitance can be given by [19]

$$
\frac{1}{C}=\frac{1}{C_{j}}+\frac{1}{C_{g}}=\frac{1}{S \varepsilon_{\circ}}\left[\frac{W}{\varepsilon_{\mathrm{c}-\mathrm{Si}}}+\frac{d}{\varepsilon_{\mathrm{P}-\mathrm{Si}}}\right]
$$

where $W$ is the depletion region width, $d$ is the porous
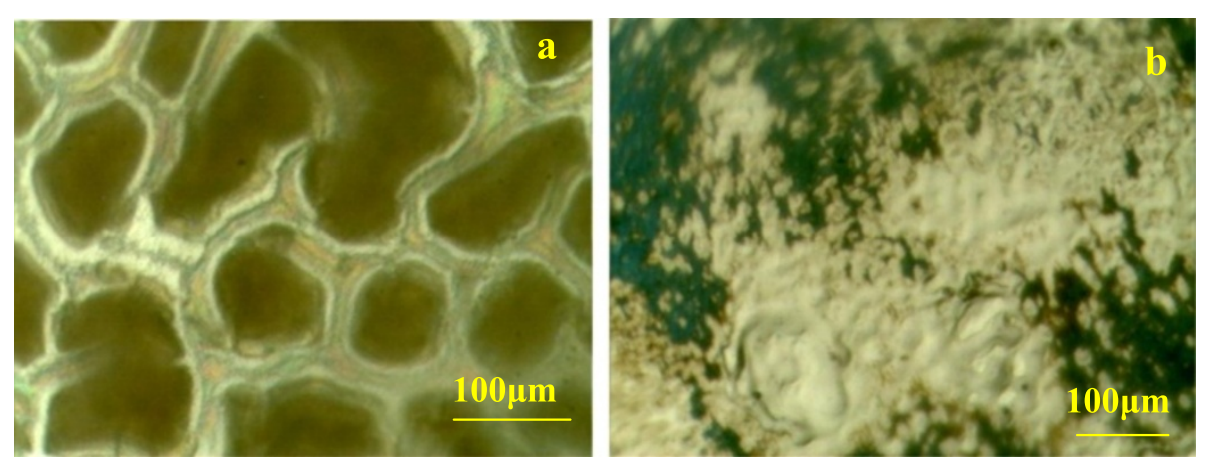

Figure 4 Microstructure of porous silicon as (a) etched and (b) after laser irradiation with $40 \mathrm{~mJ} / \mathrm{cm}^{2}$. 


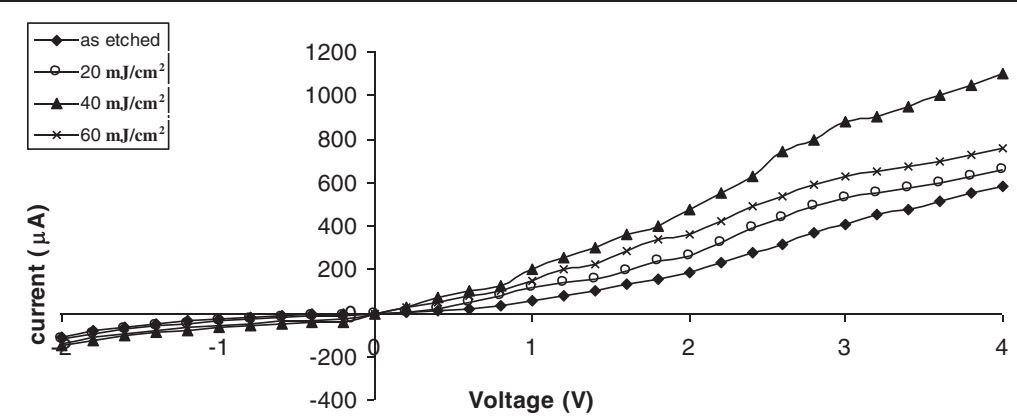

Figure 5 Dark $\mathrm{I}-\mathrm{V}$ characteristics of $\mathrm{Al} / \mathrm{PSi} / \mathrm{Si} / \mathrm{Al}$ photodetector irradiated with different laser fluencies.

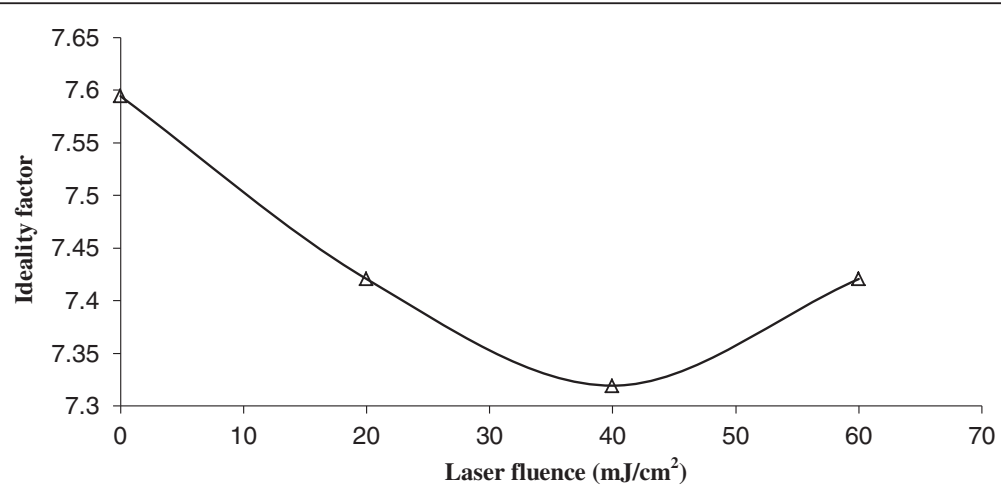

Figure 6 Effect of laser fluence on the ideality factor.

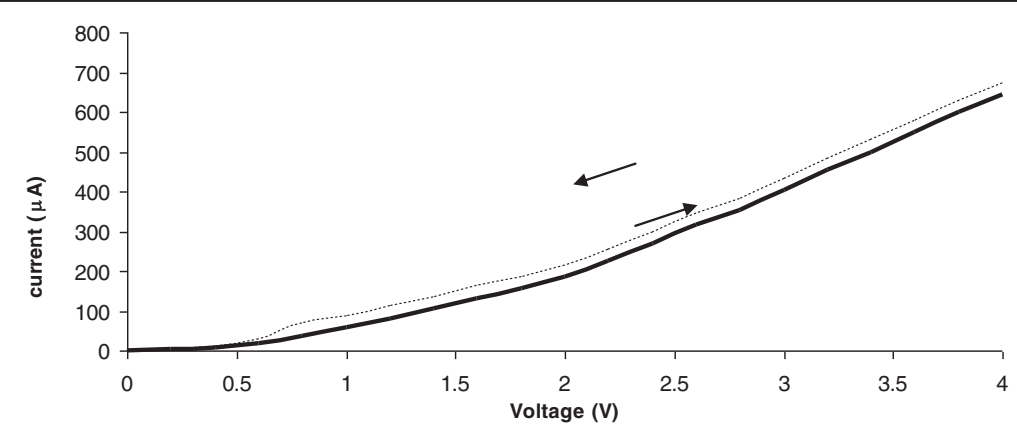

Figure 7 Dark I-V characteristics of the Al/PSi/Si/Al photodetector. 


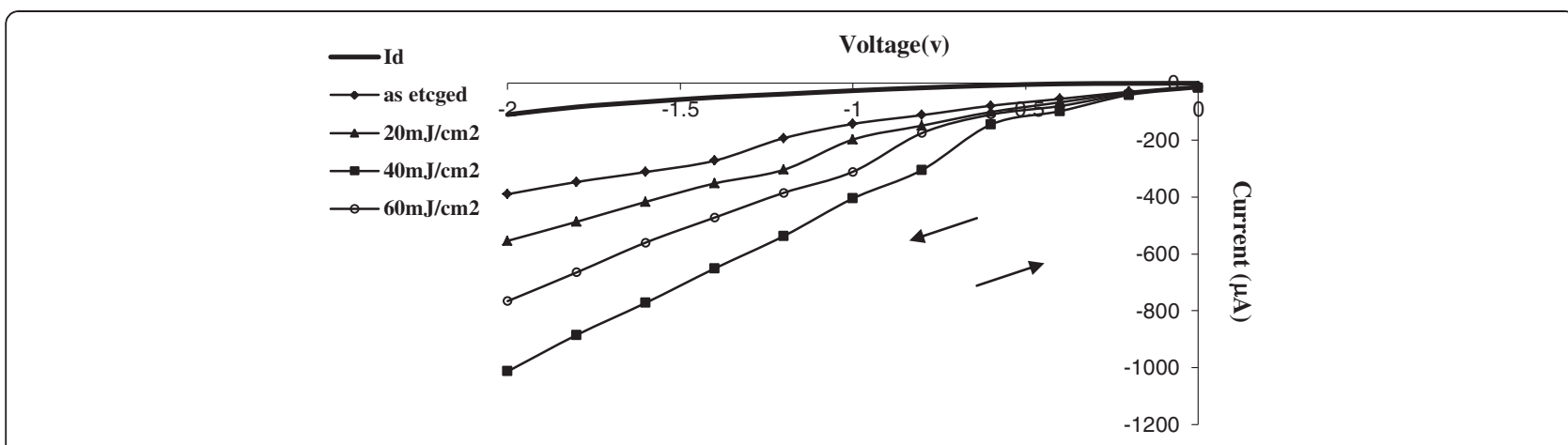

Figure 8 Photocurrent for photodetector treated with different laser fluences in reverse voltage. The photodetector is illuminated with 8 $\mathrm{mW} / \mathrm{cm}^{2}$ white light intensity.

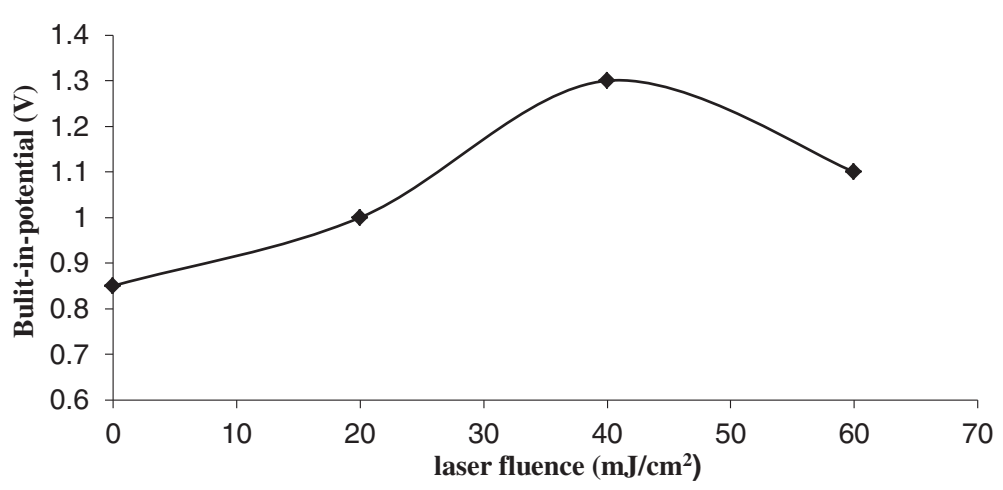

Figure 9 Effect of laser fluence on the built-in potential.

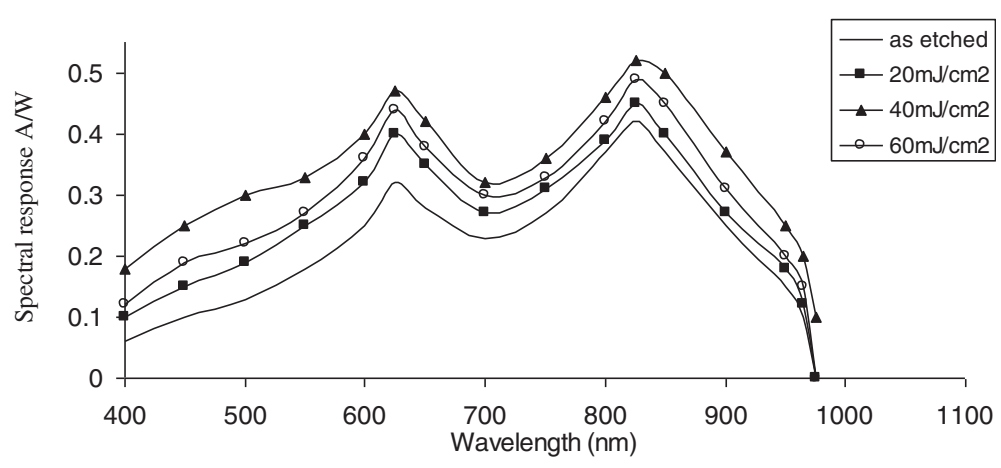

Figure 10 Spectral responsivity plot of photodetectors as a function of laser fluences. 

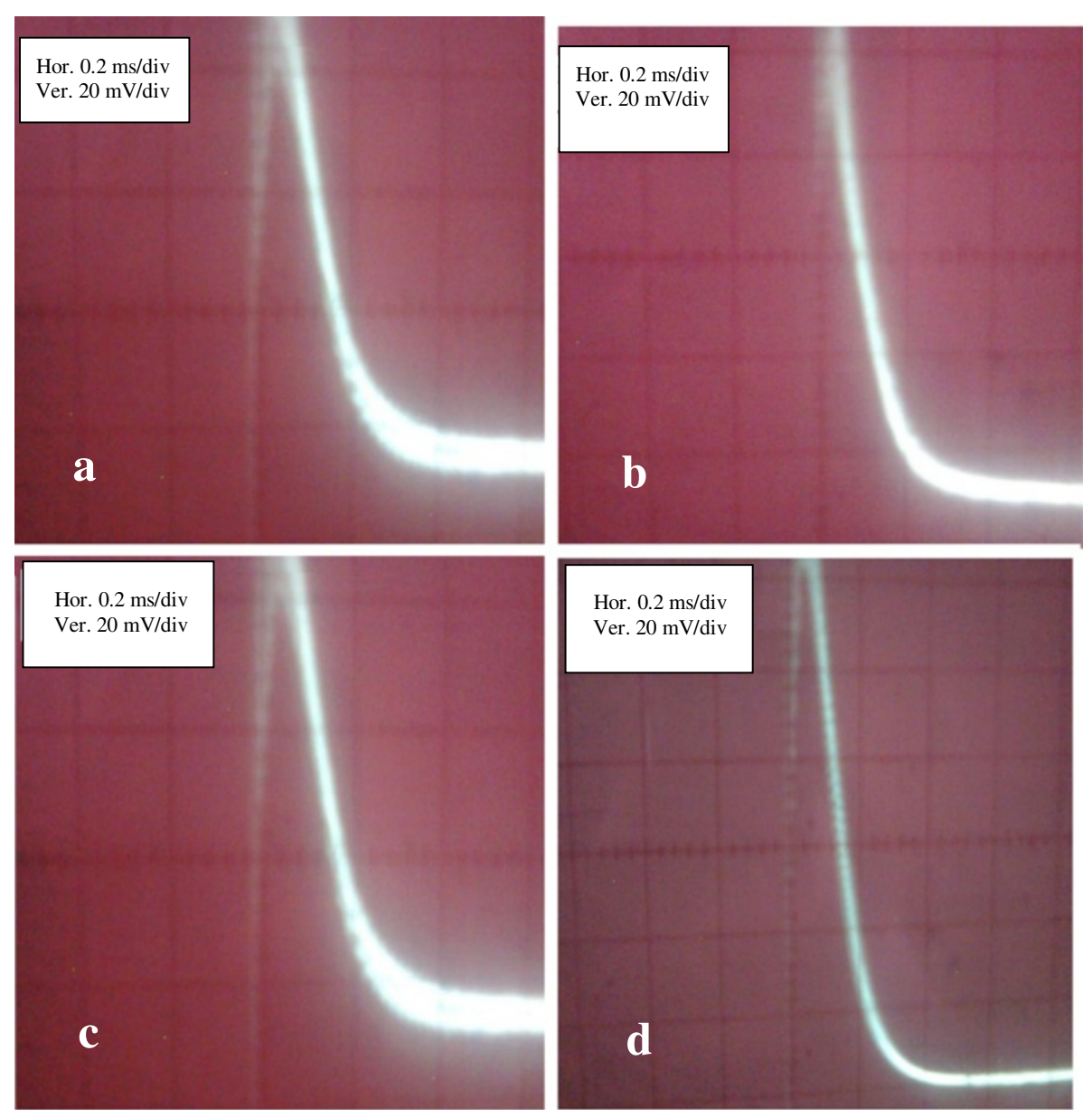

Figure 11 Images for the open-circuit voltage decay curve for AI/PSi/Si/Al diodes. (a) Before laser irradiation and after laser irradiation with (b) $20 \mathrm{~mJ} / \mathrm{cm}^{2}$, (c) $40 \mathrm{~mJ} / \mathrm{cm}^{2}$, and (d) $60 \mathrm{~mJ} / \mathrm{cm}^{2}$.

thickness, $S$ is the effective area, $\varepsilon_{\mathrm{c}-\mathrm{Si}}$ and $\varepsilon_{\mathrm{P}-\mathrm{Si}}$ are the dielectric constants of crystalline silicon and porous silicon, respectively.

$1 / C^{2}-V$ plots confirm that all the junctions are abrupt types. The value of built-in potential $V_{\mathrm{bi}}$ has been estimated and plotted as a function of laser fluence as displayed in Figure 9.

It is obvious from Figure 9 that the $V_{\mathrm{bi}}$ increased when laser fluence increased. These results are giving a good indication of improving the junction characteristics after

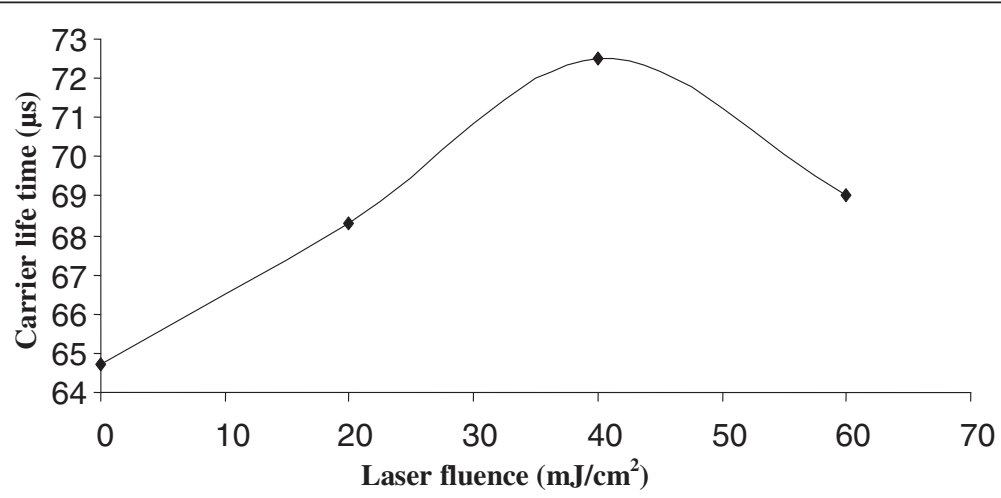

Figure 12 Carrier lifetime as a function of laser fluence. 
laser irradiation. It is clear that the values of $V_{\mathrm{bi}}$ can strongly affect the photodetector parameters such as dark current and responsivity. After irradiation with $60 \mathrm{~mJ} / \mathrm{cm}^{2}$, the junction characteristics start to degrade and $V_{\mathrm{bi}}$ is decreased. The values of $V_{\mathrm{bi}}$ for the photodetector prepared at 20 $\mathrm{mA} / \mathrm{cm}^{2}$ and irradiated by a laser fluence smaller than $60 \mathrm{~mJ} / \mathrm{cm}^{2}$ are comparable to those for a high-performance $\mathrm{Si}$ heterojunction photodetector [20,21]. Figure 10 reveals the spectral responsivity of photodetectors under the effect of laser irradiation using various laser fluences.

Two distinct peaks of response are observed: the first peak is located at $625 \mathrm{~nm}$, and the second peak is situated at $825 \mathrm{~nm}$. The first peak of response is due to the absorption of light in the depletion layer of Al-PSi, while the second peak is due to the absorption edge of bulk silicon. The value of responsivity is improved after laser irradiation. The maximum value obtained after laser irradiation using $40 \mathrm{~mJ} / \mathrm{cm}^{2}$ fluence is around $0.5 \mathrm{~A} / \mathrm{W}$ at $(\lambda=825)$. No shift in peak response has been noticed after laser irradiation. The photon-generated excess minority carrier lifetime is an important parameter in the photodetector design. The overall energy conversion efficiency of the photovoltaic cell is critically dependent upon the base region minority carrier lifetime of the cell. It can be determined by analyzing the result of the $V_{\text {oc }}$ decay curve. The carrier lifetime is calculated using the following equation:

$$
\tau=\frac{2 K T}{q}\left|\frac{1}{d V_{\mathrm{oc}} / d t}\right|
$$

where $V_{\mathrm{oc}}$ is the open-circuit voltage and $t$ is the time.

Figure 11 displays images for the open-circuit voltage decay curve for the $\mathrm{Al} / \mathrm{PSi} / \mathrm{cSi} / \mathrm{Al}$ heterojunction irradiated with different laser fluences.

Figure 12 shows the effect of laser fluence on the carrier lifetime. It is clear that the carrier lifetime increases with increasing laser fluence; that means the charge carriers have more time before recombination. This allows converting this carrier to a current. Further increasing the laser fluence leads to a decrease in the minority carrier lifetime due to the deterioration in the crystallinity quality.

\section{Conclusion}

The results presented confirmed that the laser irradiation process is a very useful and important method to enhance the porous silicon photodetector characteristics. The structural defects induced by the porous structure are minimized after laser irradiation. Photodetector figures of merit are significantly enhanced after laser treatment with a fluence of $40 \mathrm{~mJ} / \mathrm{cm}^{2}$. No shift in peak response of photodetectors has been noticed after laser irradiation.

\section{Competing interests}

The authors declare that they have no competing interests.

\section{Authors' contributions}

RAl participated in the design and construction of the electrochemical etching system, carried out the preparation of porous silicon, participated in the laser irradiation of samples, and drafted the manuscript. MKA

investigated the characteristics of silicon photodetectors and participated in the discussion of the results and analysis. Both authors read and approved the final manuscript.

\section{Acknowledgments}

The authors would like to thank Prof. Dr. Ali M. Mousa for his helpful discussion. The authors are grateful to the Applied Science Department for supporting this work.

Received: 18 May 2012 Accepted: 19 February 2013

Published: 5 March 2013

\section{References}

1. Uhlir, A: Electrolytic shaping of germanium and silicon. Bell. Syst. Tech. J. 3(5), 333 (1956)

2. Gaburro, Z, Daldosso, N, Pavesi, L: Porous silicon. In: Bassani, F, Liedl, J, Wyder, P (eds.) Encyclopedia of Condensed Matter Physics, pp. 391-401. Elsevier, Oxford (2005)

3. Astuti, B, Rusli, NI, Hashim, AM, Othaman, Z, Nafarizal, N, Ali, NK, Safi, NM: Morphological and optical characteristics of porous silicon structure formed by electrochemical etching. AIP Conf. Proc. 1341, 119 (2010)

4. Canham, L: Silicon quantum wire fabrication by electrochemical and chemical dissolution of wafers. Appl Phys Lett 57, 1046 (1990)

5. $\mathrm{Xu}, \mathrm{J}, \mathrm{Steckl}, \mathrm{AJ}$ : Visible electroluminescence from stain-etched porous $\mathrm{Si}$ diodes. Electron. Devic. Lett. 15, 507 (1994)

6. Ramizy, A, Aziz, WJ, Hassan, Z, Omar, K, Ibrahim, K: The effect of porosity on the properties of silicon solar cell. Microelectron Int 2(7), 117 (2010)

7. Alwan, AM, Jabbar, AA: Design and fabrication of nanostructures silicon photodiode. Modern Applied Science 5, 106 (2011)

8. Yu, V, D, T,T, Sieber, I, Rappich, J, Kamene, BV, Kashkarov, PK: Laser-induced melting of porous silicon. phys. stat. sol. (a) 182, 325 (2000)

9. Chistyakov, AA, Karavanski, VA, Kuznetsov, MB, Voronkova, GM, Zuev, W, Orlova, LK: On the possibility of controlling the photoluminescence spectrum of nanoporous silicon with laser radiation. AIP. Conf. Proc. 10, 881 (2000)

10. Arthur, M, Pavels, O, Fedorenko, L, Yusupov, N, Edvins, D: Suppression of pores formation on a surface of p-Si by laser radiation. Sol. St. Phen. 337, 156-158 (2009)

11. Hubarevich, Yu, HY, Wang, F, Sun, XW, Smirnov, A: Thin porous silicon fabricated by electrochemical etching in novel ammonium fluoride solution for optoelectronic applications., pp. 14-16 Photonics Global Conference, Singapore (2010)

12. Bisi, O, Ossicini, S, Pavesi, L: Porous silicon: a quantum sponge structure for silicon based optoelectronics. Surf. Sci. Rep. 38, 1 (2000)

13. Majumdar, J, Manna, I: Laser processing of materials. Sadhana 28, 495 (2003)

14. Hajji, M, Khardani, M, Khedher, N, Rahmouni, H, Bessaïs, B, Ezzaouia, H, Bouchriha, H: Structural, optical and electrical properties of quasimonocrystalline silicon thin films obtained by rapid thermal annealing of porous silicon layers. Thin Solid Films 511-512, 235 (2006)

15. Müller, G, Brendel, R: Porous silicon thermal conductivity by scanning probe microscopy. Phys. Status Solidi, A Appl. Res 182, 313 (2000)

16. Somma, F, Nikl, M, Nitsch, K, Giampaolo, C, Phani, A, Santucci, S: The growth, structure and optical properties of Csl-Pbl2 co-evaporated thin films. Superficies y Vacío 9, 62 (1999)

17. Ismail, RA: Fabrication and characterization of photodetector based on porous silicon. e-J. Surf. Sci. Nanotech 8, 388 (2010)

18. Sze, SM, Ng, KK: Physics of Semiconductor Device. Wiley, America (2007)

19. El-Nahass, MM, Abd-El-Rahman, KF, Darwish, A: Fabrication and electrical characteristics of PNi PC /n-Si heterojunction. Microelectrons J 38, 91 (2007)

20. Salem, ET: Carrier life time, time constant, and other related detector parameter for porous silicon/silicon heterojunction detector. Eng. \& Tech. J. 28, 5660 (2010)

21. Farag, $\mathrm{A}$ : Structure and transport mechanisms of Si/porous Si $n-p$ junctions prepared by liquid phase epitaxy. Appl Surf Sci 255, 3493 (2009)

doi:10.1186/2228-5326-3-11

Cite this article as: Ismail and Abood: Effect of Nd:YAG laser irradiation on the characteristics of porous silicon photodetector. International Nano Letters 2013 3:11. 